\title{
The Effect of Workplace Noise on the Hearing Threshold of Dental Technicians
}

\author{
Ju Hee Lee ${ }^{1}$, Hye Ran Lee ${ }^{2}$ and Og Kyoung Lee ${ }^{3, \dagger}$ \\ ${ }^{I}$ Department of Dental Laboratory Technology Science, Daejeon Health Sciences College, \\ Daejeon 300-711, Korea \\ ${ }^{2}$ Department of Physiology, Catholic University of Korea St. Vincent's Hospital, Gyeonggi-do 442-723, Korea \\ ${ }^{3}$ Department of Clinical Laboratory Science, Daejeon Health Sciences College, Daejeon 300-711, Korea
}

This study was conducted to investigate hypoacusis due to workplace noise among dental technicians. Pure tone audiometry, impedance audiometry and heart rate variability were measured for 60 dental technicians and office workers in D city from July to November 2013, and a survey on the effects of noise was conducted. SPSS 19.0 was used for statistical analysis. In the result for threshold of pure tone audiometry, the average hearing threshold of left ears in the air conduction (AC) test showed a statistically significant decrease $(P=0.019)$ among dental technicians, who are frequently exposed to workplace noise. The hearing threshold in the $\mathrm{AC}$ test for each frequency was significantly different between the two groups at $125 \mathrm{~Hz}(P=0.012)$ in right ears and at $1 \mathrm{kHz}(P=0.022), 2 \mathrm{kHz}(P=0.040)$, and $8 \mathrm{kHz}(P=0.018)$ in left ears. Dental technicians who had worked for 16 years or longer had a significantly higher incidence of hypoacusis in the right ear $(P=0.030)$ and in the left ear $(P=0.010)$. In impedance audiometry showed a tympanometry result of type A in both the dental technician group and the office worker group.

Key Words: Dental technicians, Heart rate variability, Impedance audiometry, Pure tone audiometry

\section{INTRODUCTION}

Noise is defined as an undesirable sound caused by machines, instruments, etc., and such noise levels are regulated according to the Industrial Safety and Health Act to protect the auditory acuity of workers against damage from strong noise in the workplace. When an excessively loud noise entering the ear arrives at the cerebral cortical auditory area through a hillock and the auditory nerve, temporary or permanent hearing loss may result. Impaired

*Received: September 17, 2014 / Revised: December 8, 2014 Accepted: December 17, 2014

${ }^{\dagger}$ Corresponding author: Og Kyoung Lee. Department of Clinical Laboratory Science, Daejeon Health Sciences College, Daejeon 300-711, Korea. Tel: +82-42-670-9162, Fax: +82-42-670-9582

e-mail: oklee@hit.ac.kr

(C) The Korean Society for Biomedical Laboratory Sciences. All rights reserved. hearing can also occur in association with pure tone components, sound impulses, and changes in sound quality or noise level (Shin, 2004; Lee, 1997).

In early noise-induced deafness, loss of the ability to hear high pitch sound is often the first symptom; therefore, impairment in everyday conversations is often not a factor. When a person notices hearing loss, the impairment is usually already quite advanced. Factors affecting a permanent audiometry threshold shift caused by noise include level of exposure, type of noise, frequency of exposure, period of exposure and personal sensitivity, which interact in a complicated fashion to finally result in hearing loss (Kim, 2004).

Dental technicians generally fashion dental prostheses and orthodontic appliances to be manually installed or implanted in the mouth or face (Shin, 2004). The manufacture of dental prostheses commonly involves equipment 
and instruments that produce noise, and the process takes place in a confined indoor space over a long period of time. In other words, dental technicians are exposed to workplace noise for long durations. Auditory damaged caused by longterm noise exposure cannot be restored; therefore, fundamental prevention measures are required (Rye et al., 2001; Kwon, 2009).

In a previous study on the working environment of dental laboratories, the satisfaction level with indoor noise in the working environment was rated 2.6 of 5 points (Hong, 2011). In a study of dental technicians, equipment vibration and indoor sound level had a positive correlation with occupational disease (Im and Min, 2001), and the possibility of noise-induced deafness has also been reported in these professionals (Nam and Cho, 1992; Dogan et al., 2008). The negative effects of noise are widely known, but studies in dental technical laboratories have been mainly focused on noise measurement (Shin, 2004; Nam and Cho, 1992), with studies on the audiometry threshold according to audiometry measurement in dental technicians being few in number.

The purpose of the present study was to investigate the audiometry threshold of workplace noise among dental technicians and to determine a correlation between physical stress and hearing by measuring heart rate variability. Based on the results, recommendations are presented on noise dampening in the dental technical environment for the prevention of permanent hearing loss.

\section{MATERIALS AND METHODS}

\section{Main subjects}

Sixty dental technicians and office workers were tested from July to November 2013. The 30 dental technicians tested had been exposed to workplace noise caused by manufacture of dental prostheses in D city. Subjects with medical diseases or who were currently taking medication that may have affected the study results were excluded from the study. Before the start of the study, researchers thoroughly explained to the participants that there were no serious adverse effects or any related hazards to participating in the research, and that all personal information would be protected. Dental technicians gave informed consent after an explanation of the study.

Subjects visited D university for hearing testing, and pure tone audiometry (air conduction, bone conduction), impedance audiometry, heart rate variability, and other medical examinations were conducted, in addition to an interview and a questionnaire survey conducted over the course of one hour. Subject recruitment was performed by phone or by visiting dental settings. As a control group, 32 office workers at D university who had not been exposed to noise at work were selected, and a total of 30 control subjects were included in the statistical analysis after excluding two subjects who did not meet the control conditions. To control for the effect of age, one of the strongest factors affecting hear loss, the average age of both groups was 45 years. Dental technicians were tested first, and then office workers of similar age were selected. The study was conducted in accordance with the regulations of the Institutional Review Board of Daejeon Health Sciences College. Informed consent was obtained from all subjects. We conducted this study only after receiving a consent form of the subjects because the IRB committee in Daejeon Health Sciences College had not been established at the time of measurement for the study (July-November, 2013).

\section{Pure tone audiometry test}

A GSI 61 Audiometer (USA) and an audiometry booth were used to conduct pure tone audiometry (PTA) in order to identify the average threshold. Pure tone audiometry measures the threshold of audibility by regulating the sound level of a pure tone in each frequency and quantitatively evaluates the level of hearing loss. The audible frequency range, which is the frequency band detectable by humans, is $20 \sim 20,000 \mathrm{~Hz}$, while the conversation band for everyday communications is $100 \sim 8,000 \mathrm{~Hz}$. Therefore, audiometry was conducted over the range of $125 \sim 8,000 \mathrm{~Hz}$ in order to identify the average hearing threshold of the conversation band. In pure tone audiometry tests, the air conduction (AC) test was performed to examine the process of sound delivering from the external ear to the inner ear $(125,250$, $500,1,000,2,000,3,000,4,000,6,000,8,000 \mathrm{~Hz})$. The test was first conducted in the ear with better hearing in the 
order of 1, 2, 3, 4, 6, $8 \mathrm{kHz}$ and again at 1,000, 500, 250, $125 \mathrm{~Hz}$. In the pure tone audiometry tests, the bone conduction (BC) test examined the process of cranial vibration delivered to the inner ear $(250,500,1,000,2,000,4,000 \mathrm{~Hz})$, and the test was first conducted for the impaired ear. The formulae of average hearing threshold used in the study are as follows:

- average threshold of the air conduction test $=(125 \mathrm{~Hz}$

$+250 \mathrm{~Hz}+500 \mathrm{~Hz}+1 \mathrm{kHz}+2 \mathrm{kHz}+3 \mathrm{kHz}+4 \mathrm{kHz}$

$+6 \mathrm{kHz}+8 \mathrm{kHz}) / 9$

- average threshold of the bone conduction test $=(250$

$\mathrm{Hz}+500 \mathrm{~Hz}+1 \mathrm{kHz}+2 \mathrm{kHz}+3 \mathrm{kHz}+4 \mathrm{kHz}) / 6$

\section{Impedance audiometry test}

The status of the eardrum and middle ear was indirectly evaluated using a GSI Tympstar tympanometer (USA). It is based upon the premise that the result of tympanometry is normal. Therefore, sensorineural hearing loss under noisy conditions may be accurately assessed, excluding conductive and mixed hearing loss.

\section{Heart rate variability}

To investigate the correlation between hearing and physical stress, the heart rate variability test and electrocardiogram (ECG) were performed using lead II. In the present study, PolyG-I (Laxtha, Korea) was used. Subjects relaxed for 30 minutes before the test. A disposable electrode was used with subjects lying on their backs. After measuring with an electrocardiogram for five minutes, changes in the R-R interval in the P-QRS-T wave, which periodically appear when the heart beats, were determined, and data was stored and analyzed using TeleScan (Laxtha, Korea) software. The activity of the sympathetic and parasympathetic (nervous) systems that together form the autonomic nervous system was measured. When the sympathetic nerve is increasingly activated, the $\mathrm{LF} / \mathrm{HF}$ ratio increases, indicating an increasing level of stress.

\section{Analysis}

The SPSS 19.0 program was used to analyze Pearson's correlation coefficient, and Independent $t$-test was used to compare the pure tone audiometry thresholds and heart rate variability between the dental technician group and the office worker group. Correlation analysis was conducted to analyze the correlation between hearing and heart rate variability. A $P$ value $<0.05$ denotes statistical significance.

\section{RESULTS}

\section{General characteristics of the subjects}

The proportions of males and females were $73.3 \%$ and $26.6 \%$, respectively, in the dental technician group and $66.6 \%$ and $33.3 \%$, respectively, in the office worker group. With regard to age groups, the largest age group was ' $>51$ years' accounting for $40.0 \%$ of subjects in both groups, and $33.3 \%$ and $23.3 \%$ of subjects were in the '41 50 years' and '31 40 years' age groups, respectively. With regard to employment period, $46.6 \%$ of subjects in the dental technician group, the largest proportion, had been employed in their profession for '21 30 years', while the highest percentages of $33.3 \%$ and $33.3 \%$ of office workers had been employed in their profession for '11 20 years' and '21 30 years', respectively. Among dental technicians, $80 \%$ of subjects held the job title of 'Head', while $50 \%$ of the office workers held the title of 'Professor' and 50\% held the title of 'Office worker'. With regard to the machines causing workplace noise, the majority $(55.2 \%)$ reported noise to be caused by 'dust suction', which was also reported by most $(63.3 \%)$ to be the instrument used for the longest amount of time (Table 1).

\section{Pure tone audiometry test}

Pure tone audiometry threshold: In the results of the average pure tone audiometry threshold of the dental technician and office worker groups, the prevalence of hypoacusis in the left ear was statistically significant in the dental technician group $(P=0.019)$ (Table 2$)$. The results of air conduction and bone conduction hearing thresholds showed a significant difference between groups in right $\mathrm{AC}$ at $125 \mathrm{kHz}(P=0.012)$ and in left $\mathrm{AC}$ at $1 \mathrm{kHz}(P=0.022)$, $2 \mathrm{kHz}(P=0.040)$, and $8 \mathrm{kHz}(P=0.018)$ (Table 3$)$.

Pure tone hearing thresholds depending on employment period: To investigate the hearing threshold of dental 
Table 1. General characteristics of the subjects $(n=60)$

\begin{tabular}{|c|c|c|c|c|c|}
\hline & & \multicolumn{2}{|c|}{$\begin{array}{l}\text { Office worker } \\
\quad(\mathrm{n}=30)\end{array}$} & \multicolumn{2}{|c|}{$\begin{array}{l}\text { Dental technician } \\
\quad(\mathrm{n}=30)\end{array}$} \\
\hline & & $\mathrm{n}$ & $\%$ & $\mathrm{n}$ & $\%$ \\
\hline \multirow{2}{*}{ Gender } & Male & 20 & 66.6 & 22 & 73.3 \\
\hline & Female & 10 & 33.3 & 8 & 26.6 \\
\hline \multirow{4}{*}{ Age (years) } & $20 \sim 30$ & 1 & 3.3 & 1 & 3.3 \\
\hline & $31 \sim 40$ & 7 & 23.3 & 7 & 23.3 \\
\hline & $41 \sim 50$ & 10 & 33.3 & 10 & 33.3 \\
\hline & $>50$ & 12 & 40.0 & 12 & 40.0 \\
\hline \multirow{2}{*}{ Marriage } & Married & 20 & 66.6 & 24 & 80.0 \\
\hline & Single & 10 & 33.3 & 6 & 20.0 \\
\hline \multirow{4}{*}{ Employment period (years) } & $1 \sim 10$ & 8 & 26.6 & 7 & 23.3 \\
\hline & $11 \sim 20$ & 10 & 33.3 & 5 & 16.6 \\
\hline & $21 \sim 30$ & 10 & 33.3 & 14 & 46.6 \\
\hline & $>31$ & 2 & 6.6 & 4 & 13.3 \\
\hline \multirow{3}{*}{ Dental technician (Duty) } & General technician & & & 4 & 13.3 \\
\hline & Chief technician & & & 2 & 6.6 \\
\hline & Head & & & 24 & 80.0 \\
\hline \multirow{2}{*}{ Office worker (Duty) } & Professor & 15 & 50.0 & & \\
\hline & General worker & 15 & 50.0 & & \\
\hline \multirow{5}{*}{ Noise machine } & Compressor & & & 6 & 20. \\
\hline & Ultrasonic cleaner & & & 2 & 6.6 \\
\hline & Motor & & & 4 & 13.3 \\
\hline & Dust suction & & & 17 & 55.2 \\
\hline & Others & & & 1 & 3.3 \\
\hline \multirow{4}{*}{ Using major machine long time } & Compressor & & & 1 & 3.3 \\
\hline & Motor & & & 9 & 30.0 \\
\hline & Dust suction & & & 19 & 63.3 \\
\hline & Others & & & 1 & 3.3 \\
\hline
\end{tabular}

Table 2. Pure tone audiometry $(n=60)$

\begin{tabular}{|c|c|c|c|c|c|c|}
\hline & \multicolumn{2}{|c|}{$\begin{array}{l}\text { Office worker } \\
\quad(n=30)\end{array}$} & \multicolumn{2}{|c|}{$\begin{array}{l}\text { Dental technician } \\
\quad(\mathrm{n}=30)\end{array}$} & \multirow[t]{2}{*}{$t$} & \multirow[t]{2}{*}{$P$} \\
\hline & Mean & SD & Mean & $\mathrm{SD}$ & & \\
\hline Right & 12.55 & 6.66 & 16.98 & 9.63 & -2.002 & 0.051 \\
\hline Left & 11.96 & 5.82 & 17.59 & 10.89 & -2.414 & $0.019^{*}$ \\
\hline
\end{tabular}

$* P<0.05$

technicians depending on occupational exposure to noise, the employment period was classified into groups of $\leq 15$ years and $\geq 16$ years. For an employment period $\leq 15$ years, there was no statistically significant difference between the dental technician group and the office worker group. For an employment period $\geq 16$ years, there was a significant difference in right ear $\mathrm{AC}(P=0.030)$ and left ear $\mathrm{AC}$ $(P=0.010)$, between the two groups (Table 4). 
Table 3. The hearing thresholds in each frequency $(n=60)$

\begin{tabular}{|c|c|c|c|c|c|c|c|c|}
\hline & & \multirow{2}{*}{$\mathrm{Hz}$} & \multicolumn{2}{|c|}{$\begin{array}{l}\text { Office worker } \\
\quad(\mathrm{n}=30)\end{array}$} & \multicolumn{2}{|c|}{$\begin{array}{l}\text { Dental technician } \\
\qquad(\mathrm{n}=30)\end{array}$} & \multirow{2}{*}{$t$} & \multirow{2}{*}{$P$} \\
\hline & & & Mean & SD & Mean & SD & & \\
\hline \multirow{15}{*}{$\mathrm{R}$} & \multirow{6}{*}{$\mathrm{BC}$} & $250 \mathrm{~Hz}$ & 4.29 & 7.66 & 5.54 & 8.31 & -.585 & 0.561 \\
\hline & & $500 \mathrm{~Hz}$ & 5.36 & 5.07 & 5.89 & 9.62 & -.260 & 0.796 \\
\hline & & $1 \mathrm{KHz}$ & 5.54 & 4.97 & 6.07 & 7.11 & -.327 & 0.745 \\
\hline & & $2 \mathrm{KHz}$ & 8.57 & 8.14 & 10.54 & 7.97 & -.912 & 0.366 \\
\hline & & $3 \mathrm{KHz}$ & 10.54 & 13.21 & 15.36 & 17.94 & -1.145 & 0.257 \\
\hline & & $4 \mathrm{KHz}$ & 11.07 & 13.00 & 13.39 & 17.43 & -.565 & 0.575 \\
\hline & \multirow{9}{*}{$\mathrm{AC}$} & $125 \mathrm{~Hz}$ & 10.71 & 6.04 & 15.71 & 8.13 & -2.611 & $0.012^{*}$ \\
\hline & & $250 \mathrm{~Hz}$ & 11.43 & 6.36 & 14.64 & 9.900 & -1.445 & 0.154 \\
\hline & & $500 \mathrm{~Hz}$ & 8.04 & 3.68 & 11.61 & 8.92 & -1.956 & 0.056 \\
\hline & & $1 \mathrm{KHz}$ & 8.21 & 4.94 & 11.25 & 6.88 & -1.894 & 0.064 \\
\hline & & $2 \mathrm{KHz}$ & 10.54 & 8.95 & 11.96 & 7.73 & -.639 & 0.526 \\
\hline & & $3 \mathrm{KHz}$ & 12.68 & 14.49 & 18.04 & 18.92 & -1.189 & 0.240 \\
\hline & & $4 \mathrm{KHz}$ & 16.96 & 14.86 & 21.61 & 19.72 & -.995 & 0.324 \\
\hline & & $6 \mathrm{KHz}$ & 16.25 & 13.09 & 23.93 & 19.92 & -1.704 & 0.094 \\
\hline & & $8 \mathrm{KHz}$ & 18.21 & 13.62 & 24.11 & 19.15 & -1.327 & 0.190 \\
\hline \multirow{15}{*}{$\mathrm{L}$} & \multirow{6}{*}{$\mathrm{BC}$} & $250 \mathrm{~Hz}$ & 2.14 & 6.29 & 4.29 & 8.68 & -1.057 & 0.295 \\
\hline & & $500 \mathrm{~Hz}$ & 5.36 & 5.92 & 4.64 & 7.06 & .410 & 0.683 \\
\hline & & $1 \mathrm{KHz}$ & 4.11 & 4.72 & 4.46 & 7.61 & -.211 & 0.834 \\
\hline & & $2 \mathrm{KHz}$ & 6.96 & 5.82 & 11.25 & 9.96 & -1.964 & 0.055 \\
\hline & & $3 \mathrm{KHz}$ & 10.00 & 12.54 & 15.18 & 16.47 & -1.324 & 0.191 \\
\hline & & $4 \mathrm{KHz}$ & 9.46 & 9.93 & 14.11 & 16.33 & -1.285 & 0.204 \\
\hline & \multirow{9}{*}{$\mathrm{AC}$} & $125 \mathrm{~Hz}$ & 11.43 & 5.75 & 14.11 & 7.82 & -1.460 & 0.150 \\
\hline & & $250 \mathrm{~Hz}$ & 10.36 & 6.79 & 13.39 & 9.33 & -1.391 & 0.170 \\
\hline & & $500 \mathrm{~Hz}$ & 8.39 & 5.10 & 11.43 & 6.36 & -1.970 & 0.054 \\
\hline & & $1 \mathrm{KHz}$ & 7.32 & 3.96 & 10.71 & 6.48 & -2.362 & $0.022^{*}$ \\
\hline & & $2 \mathrm{KHz}$ & 8.39 & 6.53 & 13.39 & 10.72 & -2.107 & $0.040^{*}$ \\
\hline & & $3 \mathrm{KHz}$ & 11.96 & 13.07 & 17.50 & 16.35 & -1.399 & 0.168 \\
\hline & & $4 \mathrm{KHz}$ & 16.07 & 12.57 & 22.32 & 19.07 & -1.448 & 0.154 \\
\hline & & $6 \mathrm{KHz}$ & 17.32 & 13.15 & 26.96 & 23.38 & -1.902 & 0.063 \\
\hline & & $8 \mathrm{KHz}$ & 16.43 & 12.00 & 28.57 & 23.48 & -2.436 & $0.018^{*}$ \\
\hline
\end{tabular}

$* P<0.05$, R: Right, L: Left

$\mathrm{AC}$ : Air conduction, $\mathrm{BC}$ : Bone conduction

\section{Impedance audiometry test}

The tympanometry test was conducted in the dental technician and office worker groups. In this test, the external auditory canal was completely blocked with a probe, while information on dynamic compliance, static compliance and peak compliance were collected to determine the level of eardrum movement on presentation of a noise. The results showed that both the dental technician and the office worker group were type A (Fig. 1). Type A means that the external ear or middle ear is normal or sensorineural hearing loss appears. Therefore, it was indirectly confirmed that the 
Table 4. The pure tone hearing thresholds depending on the employment period $(n=60)$

\begin{tabular}{|c|c|c|c|c|c|c|c|}
\hline \multicolumn{8}{|c|}{ Employment period $\leq 15$ years } \\
\hline & & \multicolumn{2}{|c|}{$\begin{array}{l}\text { Office worker } \\
\quad(n=12)\end{array}$} & \multicolumn{2}{|c|}{$\begin{array}{c}\text { Dental technician } \\
(\mathrm{n}=11)\end{array}$} & \multirow{2}{*}{$t$} & \multirow{2}{*}{$P$} \\
\hline & & Mean & SD & Mean & $\mathrm{SD}$ & & \\
\hline \multirow{2}{*}{$\mathrm{R}$} & $\mathrm{BC}$ & 4.50 & 3.83 & 2.41 & 3.55 & 1.231 & 0.235 \\
\hline & $\mathrm{AC}$ & 7.83 & 2.99 & 8.27 & 2.21 & -0.359 & 0.724 \\
\hline \multirow{2}{*}{$\mathrm{L}$} & $\mathrm{BC}$ & 3.75 & 3.00 & 3.70 & 3.66 & 0.030 & 0.976 \\
\hline & $\mathrm{AC}$ & 7.56 & 3.45 & 8.33 & 2.22 & -0.577 & 0.572 \\
\hline \multicolumn{8}{|c|}{ Employment period 16 years $\leq$} \\
\hline & & \multicolumn{2}{|c|}{$\begin{array}{l}\text { Office worker } \\
\quad(\mathrm{n}=18)\end{array}$} & \multicolumn{2}{|c|}{$\begin{array}{l}\text { Dental technician } \\
\quad(\mathrm{n}=19)\end{array}$} & \multirow{2}{*}{$t$} & \multirow[t]{2}{*}{$P$} \\
\hline & & Mean & SD & Mean & SD & & \\
\hline \multirow{2}{*}{$\mathrm{R}$} & $\mathrm{BC}$ & 9.26 & 7.28 & 12.81 & 8.22 & -1.387 & 0.174 \\
\hline & $\mathrm{AC}$ & 15.19 & 6.68 & 21.11 & 9.01 & -2.263 & $0.030^{*}$ \\
\hline \multirow{2}{*}{$\mathrm{L}$} & $\mathrm{BC}$ & 7.78 & 5.61 & 11.49 & 8.08 & -1.615 & 0.115 \\
\hline & $\mathrm{AC}$ & 14.41 & 5.46 & 21.99 & 10.60 & -2.708 & $0.010^{*}$ \\
\hline
\end{tabular}

$* P<0.05$, R: Right, L: Left

$\mathrm{AC}$ : Air conduction, $\mathrm{BC}$ : Bone conduction

TYMP DIAGNOSTIC

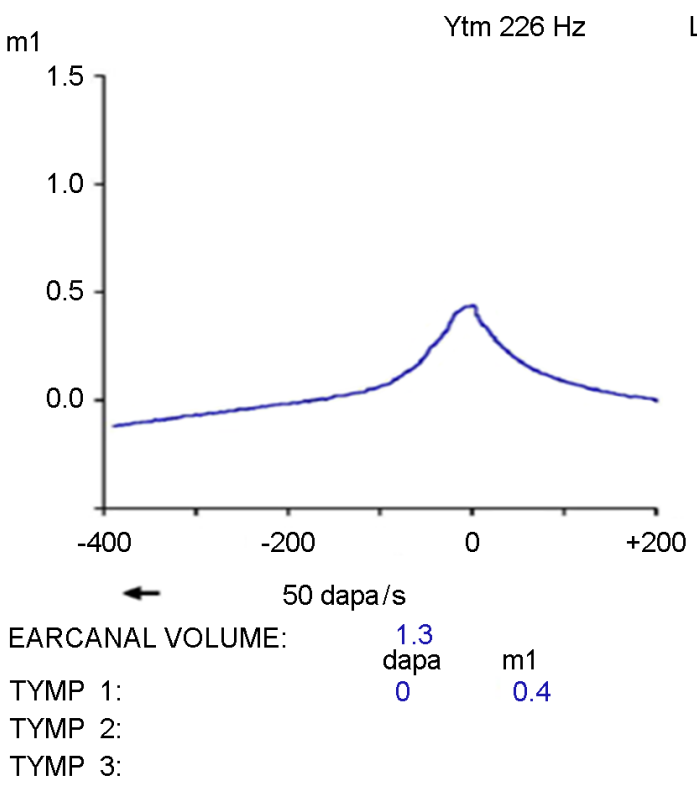

Fig. 1. Tympanometry test. In impedance audiometry, the result of tympanometry was type A graph.

external ear and middle ear were normal in both groups. This result was used to identify the existence and level of hearing loss due to noise, excluding hearing loss caused by lesions in the external ear or middle ear.

\section{Heart Rate Variability}

Heart rate variability: In the examination of heart rate variability to investigate the correlation between auditory acuity and stress, there was no statistically significant difference between the dental technician and office worker groups (Table 5).

Correlation between auditory acuity and heart rate variability: There was no significant correlation between the pure tone audiometry threshold and heart rate variability.

\section{DISCUSSION AND CONCLUSIONS}

In general characteristics of the dental technician group, the machine making the loudest noise was 'Dust suction' as $55.2 \%$ and used for the longest time, at $63.3 \%$. Therefore, noise management of dust suction is required. With regard to the pure tone auditory acuity test for the dental technician and office worker groups, hypoacusis in the left ear was 
Table 5. Heart Rate Variability $(n=60)$

\begin{tabular}{|c|c|c|c|c|c|c|}
\hline & \multicolumn{2}{|c|}{$\begin{array}{l}\text { Office worker } \\
\quad(n=30)\end{array}$} & \multicolumn{2}{|c|}{$\begin{array}{l}\text { Dental technician } \\
\quad(\mathrm{n}=30)\end{array}$} & \multirow[t]{2}{*}{$t$} & \multirow{2}{*}{$P$} \\
\hline & Mean & SD & Mean & SD & & \\
\hline $\mathrm{LF} / \mathrm{HF}$ & 2.36 & 1.59 & 2.79 & 1.63 & 0.972 & 0.336 \\
\hline Norm LF & 0.64 & 0.15 & 0.69 & 0.12 & 1.356 & 0.181 \\
\hline Norm HF & 0.36 & 0.15 & 0.30 & 0.12 & -1.356 & 0.181 \\
\hline Mean HRV & 71.13 & 9.19 & 74.57 & 12.88 & 1.137 & 0.260 \\
\hline
\end{tabular}

Mean HRV: mean heart rate variability, LF: Low frequency, HF: High frequency

statistically significant in the dental technician group. This result is in accord with a previous study reporting that $40 \%$ of cases of hypoacusis due to noise were asymmetric, with a greater than $20 \mathrm{~dB}$ difference in hearing threshold and more severe hypoacusis in the left ear (Kim, 2004). The cause of this ear discrepancy is not clear, but it was suggested that sensitivity to noise might be higher in the left ear (Kim, 2004). The cause has not been clearly verified and, therefore, further studies are required to investigate the effects on the working posture of dental technicians and the direction of noise exposure.

With regard to the air conduction hearing thresholds, there was a significant difference between groups in the right ear at $125 \mathrm{~Hz}$ and in the left ear at $1 \mathrm{kHz}, 2 \mathrm{kHz}$, and $8 \mathrm{kHz}$. These significant differences in auditory acuity at frequencies higher than $2 \mathrm{kHz}$ indicate that hearing loss is more common in dental technicians than in office workers. This result is in accord with a previous study reporting that the hearing threshold in a group exposed to occupational noise was decreased compared to that of a non-exposed group (Kim et al., 2008). No significant differences were observed in the bone conduction test in the present study.

To investigate hearing threshold according to occupational exposure of noise in the dental technician group, the employment period was classified into groups of $\leq 15$ years and $\geq 16$ years. In subjects with an employment period $\geq 16$ years, there was a significant difference in right ear $\mathrm{AC}$, left ear $\mathrm{AC}$ between the two groups. Therefore, hypoacusis due to long-term noise exposure was concluded. This is in contrast to a study conducted by Kim (Kim, 2006) in which the severity of hearing loss in a noise-exposed group did not increase as the employment period increased.

Fundamental methods to protect workers from noise include installation of sound absorption mechanisms, modification of the audible machinery or working processes, and installation of partitions in noisy locations in effort to block or seal out noise (Ministry of Labor 2008, 2010). In situations in which it is difficult to implement these methods, auditory protective equipment, such as earplugs and ear caps, are to be provided. When auditory protective equipment is worn properly, the detectable noise level can be decreased by 7 dB (Kim, 2008).

There are no previous studies on the auditory acuity measurement in dental technicians because it is hard to move equipment for diagnosis in the auditory acuity measurement, and so dental technicians have to visit the medical examination location by taking time off of work. Therefore, there may be realistic difficulties. Permanent hypoacusis caused by noise cannot be repaired. Therefore, supplementary studies with a larger number of dental technicians are needed to generalize the results and to highlight the importance of hearing loss prevention.

\section{Acknowledgements}

This paper was supported by Daejeon Health Sciences College in 2014.

\section{REFERENCES}

Dogan DO, Ozdemir AK, Polat NT, Dal U, Gumus C, Akkurt I. Prevalence of hearing loss on dental laboratory technicians exposed to noise. The Anatolian Journal of Clinical 
Investigation. 2008. 2: 113-117.

Hong YH. Evaluation of work environment and occupational exposure to dental technicians, Department of Public Health The Graduate School. Catholic University of Daegu. 2011. 1-3: 107.

Im BC, Min GJ. A Study on the occupational diseases of the dental technicians and the related factors in Korea. Korean Society for Health Education and Promotion. 2001. 18: 41 $-156$.

Kim JS. Noise exposure assessment and noise reduction efficiency comparison according to improvement in a petrochemical plant. Unpublished Master's Thesis. University of Catholic University Deagu. 2008. 6-8.

Kim KS. Distribution of hearing thresholds and hearing loss among noise-exposed workers. Communication Sciences and Disorders. 2006. 11: 106-121.

Kim NJ, Kwon JK, Lee JH. The impact of noise Expose on the hearing threshold extended high frequency. Korean J Occup Environ Med. 2008. 20: 81-92.

Kim WT. Hearing asymmetry among occupationally noise-exposed workers, a Master's degree of Dept. Science in Medicine of
Inje University. 2004. 1-3.

Kwon HJ. A Study on a Self hearing test to prevent noise induced hearing loss. Master's degree of Dept. of Information \& Telecommunication Graduate School Soongsil University. 2009. 50.

Lee GT. Study on the trends and problems of noise measuring and rating method. Theses Collection of The Institute of Advanced Materials. 1997. June: 225-255.

Ministry of Labor 2008. Employees health examination results (Issue Brief No. 11-1490000- 000066-10). Seoul: Author. January 2010.

Nam SY, Cho SY. A study on the noise by working process in dental laboratory. J Kor Env Hygi Sci. 1992. 2: 97-107.

Rye SH, Kwon YJ, Lee SJ, Song JC. A Study on noise induced hearing loss of employees working for Seoul metropolitan subway cooperation. The KJAsEM. 2001. 11: 37-44.

Shin DY. The relation between the present status of a noise within the dental laboratory and stress, a Master's degree of Dept. of Community Health The graduate School of Social Development Chung-Ang University. 2004. 1-4. 